\title{
Quality Analysis Of Service (QOS) to Measuring Quality Topology Network Computer-Based National Exam (UBNK)
}

\author{
Muhammad Imam Ghozali ${ }^{1,}$ Alif Catur Murti ${ }^{2}$, Ratih Nindyasari ${ }^{3}$, Wibowo Harry \\ Sugiharto $^{4}$, Muhammad Malik Hakim ${ }^{5}$ \\ \{imam.ghozali@umk.ac.id ${ }^{1}$, alif.catur@umk.ac.id ${ }^{2}$, ratih.nindyasari@umk.ac.id $\left.{ }^{3}\right\}$ \\ Department of Informatic Engineering, Faculty of Engineering, Universitas Muria Kudus, Kudus - \\ Indonesia1234 ${ }^{12345}$
}

\begin{abstract}
The need for the availability of fast network services, network stability, and compatibility with the technology used to be the primary needs for the community. Implementation in the use of technology today has touched all aspects of life. The educational aspect is one that is affected by technological developments, especially the internet. The real shape of the impact is the Standard Oprasional Procedure (POS) issued by the National Education Standards Agency (BNSP) in 2017 for the National Computer Based Examination (UNBK). These conditions make some schools that become pilot prepare by starting to build exam room designed with computer equipment and internet network. Quality of Service Analysis (QoS) is used to determine the quality of internet network topology that is built, so the final goal of productivity, and efficiency can increase.
\end{abstract}

Keywords: topology network, computer network, QoS.

\section{Introduction}

Nowadays, the speech of internet access become the important things of internet service providers. The speed of internet is influenced not only from the provider itself but also in terms of design of a computer network topology that is used. The topology of internet network must be adjusted with the needs of the environment. For example is the building form and the availability of resources. The exact of network topology will increase the effectiveness, efficiency, and productivity of the user.

The measurement quality of computer network is done by Standard Quality of Service (QoS)[1]. It has been designed to help user become more productive by ensures that users get the best quality from a computer network. QoS also provides the quality of computer network even it uses different technologies. The quality of a computer network is influenced by bandwidth, distance and traffic in the network topology[2]. QoS have a feature to predict the needs of the bandwidth that is adjusted for distance[3]. The main purpose of this research is to know topology which have speech high communication data and eficient in constraction $\operatorname{cost}[2][3]$.

The type of computer network topology is Point to Point, Multipoint, BUS, Ring, Star, Tree, Mesh and Hybrid. The Topology is researching is the Hybrid topology that uses router

ICCSET 2018, October 25-26, Kudus, Indonesia

Copyright (C) 2018 EAI

DOI 10.4108/eai.24-10-2018.2280551 
mikrotik and it does not use router. The result applying topology and good hardware placement will show better and equal, as well as more secure IP address management. The choice of network topology and the proper hardware placement will provide better impact of network usage and also to avoids the occurance of IP Address conflict in every unit.

QoS is a method of measuring to know how well the network is instaleed and it's also an attempt to define the characteristics and the properties of a service[4][5]. QoS is used to measure a set of performance attributes that have been specified and associated with a service. QoS parameters that is used to data communication service analysis are jitter, packet loss, throughtput, and delay[3][5][6]. By using the QoS parameters above, it will be known the category value of QoS index of data communication services for the current national examination. The result will be measured internet network and then it's determined the value of index parameter. Then the results will be analyzed in order to be optimized as a consideration of the application of network topology during the national exam. So, the quality of network is applied more effect and data communication quality is more reliable. Research about the use of QoS to measure the quality of the Internet network ever done in UPT Loka Technical Test Development Jambang Kulon-LIPI[7]. In this research,QoS is used to measure the quality of internet network[8][9]. In this study the author uses sniffing tools as a measurement of QoS[8]. it is also a tool used to discover problems that exist on the network[8]. QoS is called to have a feature to predict the needs of the bandwidth adjusted for distance[8]. Research on network topology design has been conducted for the design and development of VLAN networks[10]. In this study focuses on how to improve network performance with multiple divisions that separate each other by comparing two network models[10]. The trial of this research uses a tool in the form of a packet tracer application, which allows the application to design a large virtual network with addressing details (addresing) computer[10]. The results of this study show the configuration of VLANs by using the trunking switch method associated with the router can improve network performance[10].

The difference of this research with previous research likes in the design concept of network topology built and adapted to the integrity of UNBK which is then measured its quality by using QoS standard.

\section{Top Down Network Design}

Top Down Network Design is a discipline that combines software programming and software analysis[11][12][13]. The purpose of using this topology is to divide up a project to be easily replaced and in maintance. Top Down Network Design is divided into 4 major steps[12]:

a. Analysis of interview problems to the user to understand the business processes that occur and can make the goal of the new system that will be made.

b. Logical network design: In this phase, network analysis will create a new network system topology.

c. Physical network design: Network analysis will select the technology and hardware to be used.

d. Testing, optimization, and network design documentation: The final step in Top Down Network Design is to implement a network that has been created. 


\subsection{Analysis}

The analytical method uses the Top Down Approach and uses the LAN Technologies Choices model[11][12]. In connection with data analysis, through Top Down Network Design then the data obtained will be made into a design[12][13]. This design will create an interconnect network topology design drawing to be constructed, it is hoped that this drawing will give a complete picture of the existing needs. Design can be a topology structure design, data access design, layout layout design, etc. which will give a clear picture of the project to be built. As an analysis in this study topology model that is in use today using Tree topology, with sequence hardware Modem, Switch and computer at each laboratory. In this study the authors provide a description of the design of the appropriate topological structure.

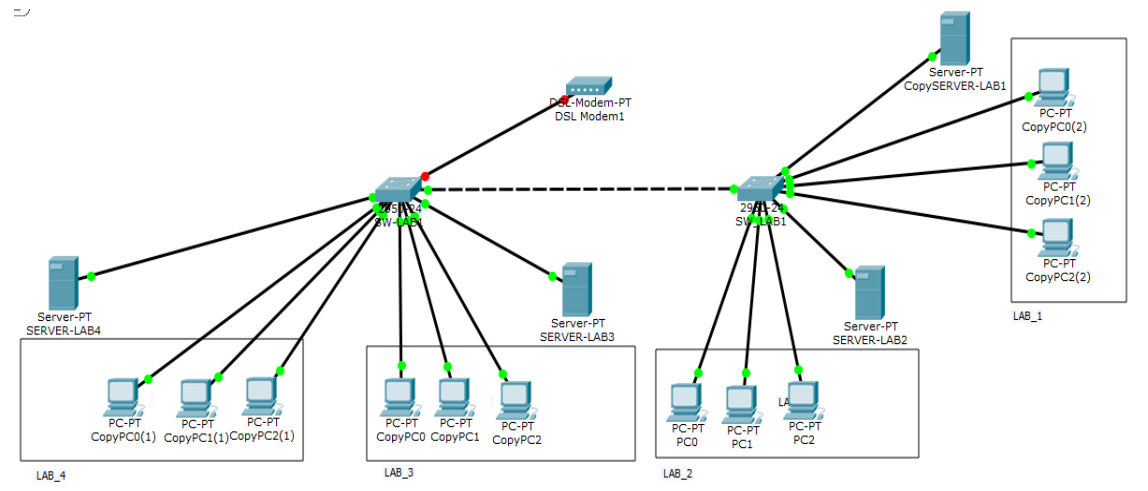

Fig. 1.The Current topology design.

\subsection{Quality of Service (QoS)}

Quality of Service (QoS) is the ability of a network to provide good services by providing bandwidth, overcoming jitter and delay[6][8][14]. The purpose of the QoS mechanism is to influence at least one of the four basic parameters of a given QoS. QoS is designed to help end users become more productive by ensuring that users get reliable performance from networkbased applications. QoS refers to the ability of the network to provide better service on certain network traffic through different technologies[5][15]. QoS is a big challenge in IP Address and internet based networks as a whole. The purpose of QoS is to meet different service needs, which use the same infrastructure. QoS offers the ability to define the service attributes provided, both qualitatively and quantitatively[16] .

\subsection{Mikrotik}

Mikrotik are tools (i.e. routers, switches, antenna, and other supporting devices) and software (MikroTik RouterOS) based on Linux that serve for internet connectivity. Mikrotik has created by John Trully and Arnis Riekstins in 1996. As simply, Mikrotik is a router operating 
system that regulates the network activities[8][17]. In this study, Mikrotik will be used as an operating system that support software and hardware devices for bandwidth management[17].

\subsection{Bandwidth}

There are many solutions in the existing research literature for measuring the available bandwidth. A lot of tools for bandwidth measurement are developed and used for measuring the available bandwidth. The most important methods for measuring the available bandwidth are packet rate and packet gap method[1][17][18]. Solutions for measuring the available bandwidth using the packet rate method are obtained with the tools Pathload[1][17][18].

\subsection{Throughput}

Troughput is the total number of successful packet arrivals that observed on the destination over a specified time interval divided by the duration of the time interval. Throughput is the actual ability of a network to deliver data. Usually throughput is always associated with bandwidth. Throughput is the rate (speed) of active data transfer, thatmeasured in bits per second (bps). The formula for calculating the throughput value is as follows[8][16]:

$$
\text { throughput }=\frac{\text { Jumlah datayangdikirim }}{\text { Waktupengirim }}
$$

In TIPHON standard throughput is calculated in percent, to get throughput value in percent throughput calculation results then divided by the amount of bandwidth value and multiplied by $100 \%$ to know the percentage of actual throughput value.

$$
\text { Throughput } \%=\frac{\text { Bandwidth }}{\text { Throughput }} \times 100 \%
$$

\section{Result and Discussion}

This section describes the comparison of QoS parameter values by applying the existing topology and the suggested topology. The first stage, network topology implementation without using a router. And the second stage, analyzing QoS parameters by previously providing ping request activity between computers in each laboratory. The same test is performed on the recommended topology design. The testing results become the reference for physical design and chosen media networks .

\subsection{QoS Existing Network Measurement}

QoS test uses ping observation from computer with ip address 192.168.111.250 to computer with ip address 192.168.111.220, where ip address is still in single segment accompanied with 
sniffing activity. Based on the design of computer network topology in Fig. 2, by applying tree topology without using router.

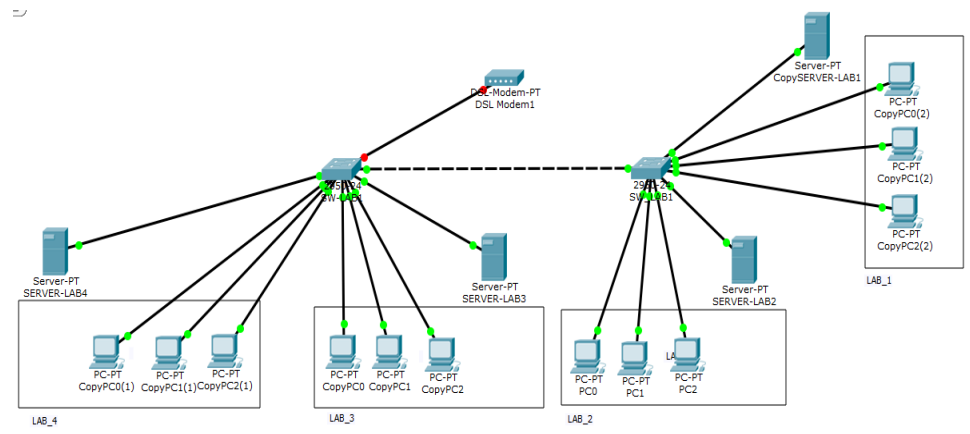

Fig. 2. Design exiting network.

QoS measurement is done when one computer in lab 1 to copy the existing file on the lab server 4. Testing delivery of data packets from source to destination or otherwise has an error on the TCP protocol, as shown in Figure Fig.3. The impact of errors on the TCP protocol then the data transmission is also interrupted, this is evidenced by the missing packet when packet delivery. Observation of stability of TCP protocol in packet delivery here is done approximately 5 minutes. Packet data when the delivery experience up and down following the stability of the network connection is influenced one of the TCP protocol. From observing packet loss delivery like fig. 4 .

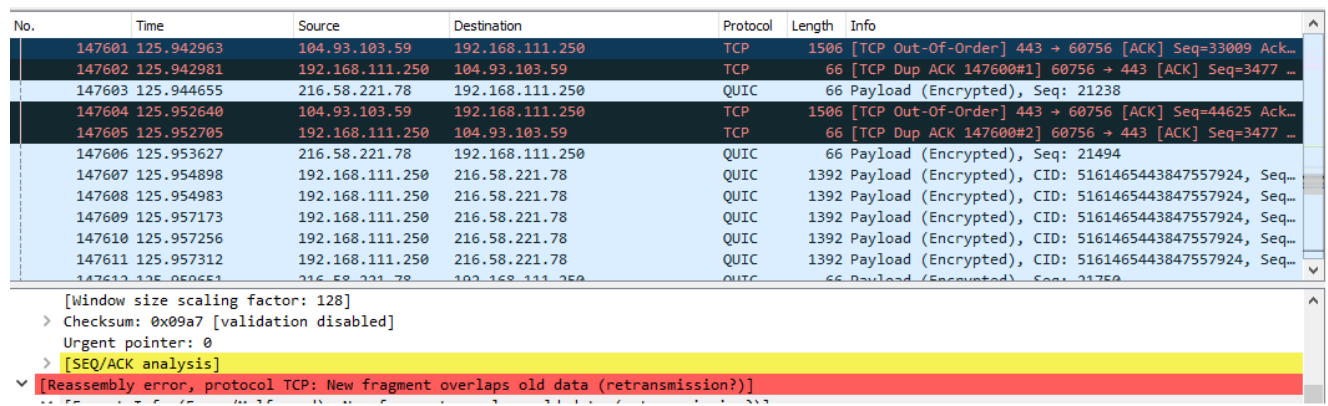

Fig. 3. TCP protocol errors. 


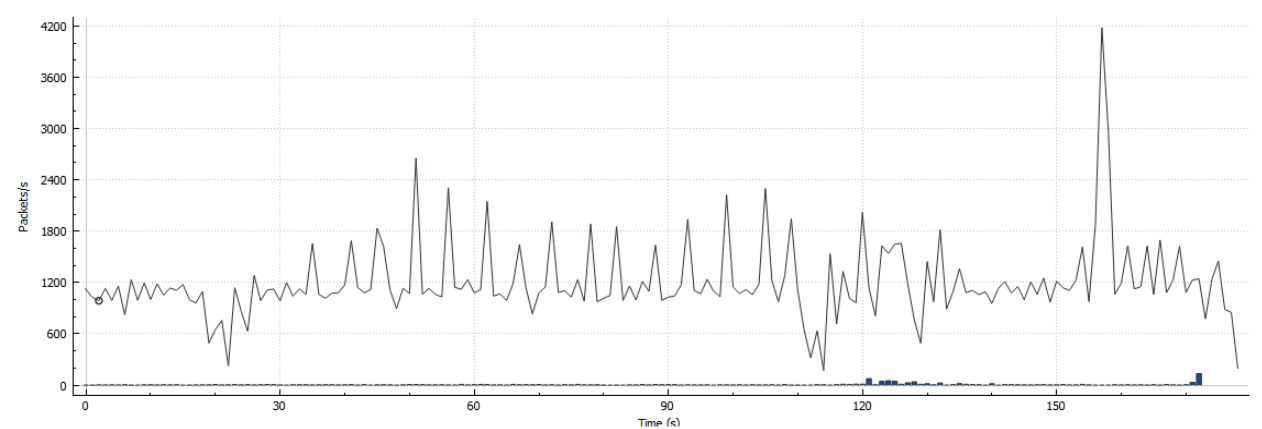

Fig. 4. Packet loss graph.

\subsection{QoS of Network Design Measurement}

In the Network topology scheme of this proposed, by providing a router after the modem before heading to the main switch and to the switches of each lab. The load given during the test is the same as the previous topology. Proposed topology design can be seen in fig.5.

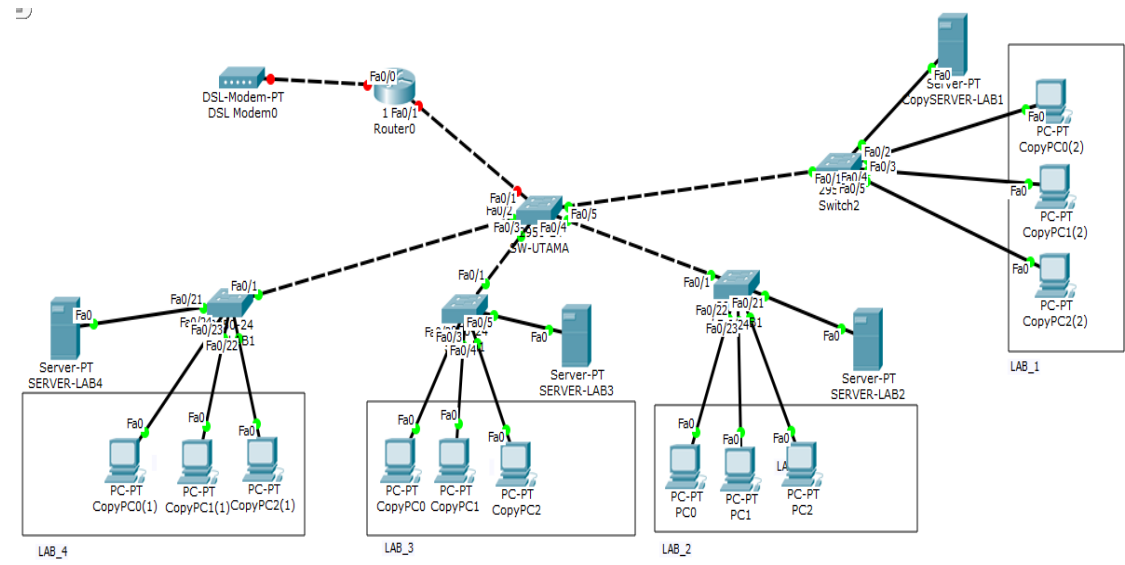

Fig. 5. Design exiting network.

QoS measurement is done when one computer in lab 1 to copy the existing file on the lab server 4. Testing delivery of data packets from source to destination or conversely. The results of test shown in Figure Fig.6. The observations of the are converted in graphical form to display the packet delivery process and to see the stability of the TCP protocol. Packet data delivery experience fluctuations resulting from bandwidth allocation. The result of packet data fluctuations can be seen in fig.7. 


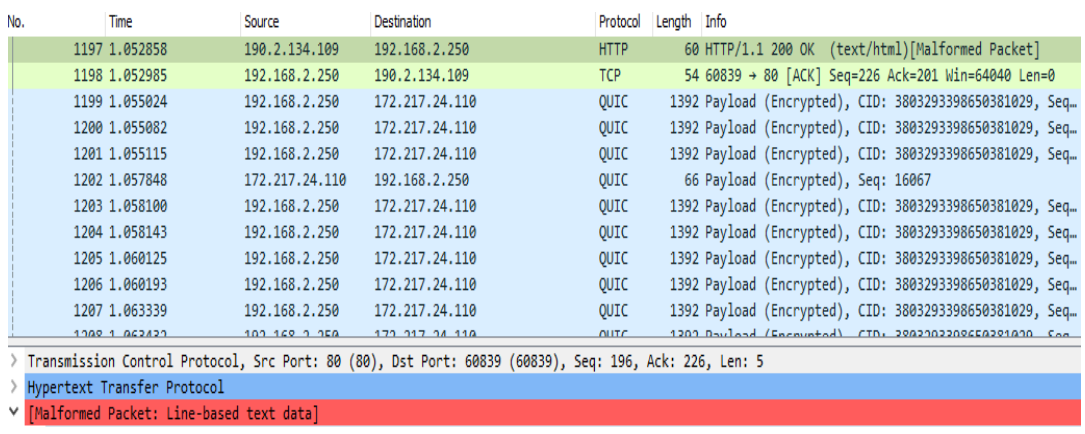

Fig. 6. Purpose network design.

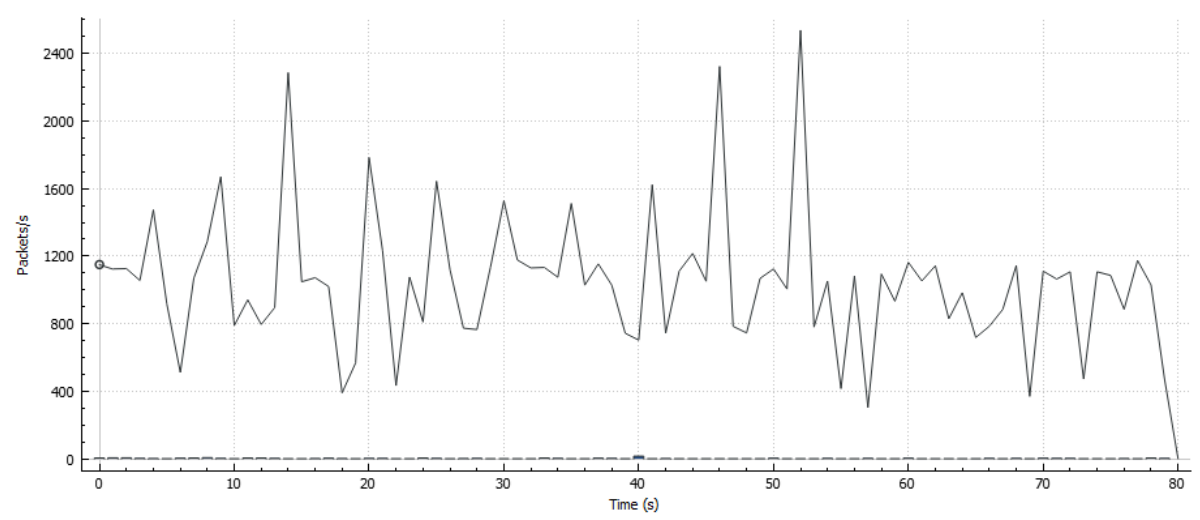

Fig. 7. Purpose packet loss graph with network.

\section{Conclusion}

Based on results of testing, observation and analysis, can be drawn some conclusions. First, QoS quality on the previously applied topology is inconsistent in packet delivery, as seen from some packet loss sending back. Second, implementation of the router on a computer network topology has not been a guaranted that the QoS quality in the topology is well maintained. Third, the quality of QoS of each applied topology, influenced by the bandwidth allocation. Overall quality of hardware used also affects the QoS results themselves. 


\section{References}

[1] K. Jakimoski, S. Arsenovski, L. Gorachinova, S. Chungurski, O. Iliev, L. Djinevski, And E. Kamcheva, "Measurements Of Available Bandwidth In Computer Networks," Int. J. Grid Distrib. Comput., Vol. 9, No. 4, Pp. 201-210, 2016.

[2] A. Anjum And S. A. Pasha, "-A Brief View Of Computer Network Topology For Data Communication And Networkingl," Int. J. Eng. Trends Technol., Vol. 22, No. 7, Pp. 319-324, 2015.

[3] M. Jain And C. Dovrolis, "Pathload: A Measurement Tool For Available Bandwidth Estimation," Proc. Pam2003, 2002.

[4] C. Courcoubetis And V. A. Siris, "Measurement And Analysis Of Real Network Traffic," In Proc. 7th Hellenic Conference On Informatics, 1999.

[5] M. H. Miraz, M. A. Ganie, S. A. Molvi, M. Ali, And A. H. Hussein, "Simulation And Analysis Of Quality Of Service ( Qos ) Parameters Of Voice Over Ip ( Voip ) Traffic Through Heterogeneous Networks,” Int. J. Adv. Comput. Sci. Appl., Vol. 8, No. 7, Pp. 242-248, 2017.

[6] R. S. L. Dan M. Pinem, "Analisis Quality Of Service (Qos) Jaringan Internet Di Smk Telkom Medan," Singuda Ensikom, Vol. 7, No. 3, P. 1, 2014.

[7] R. Wulandari, “Analisis Qos (Quality Of Service) Pada Jaringan Internet (Studi Kasus : Upt Loka Uji Teknik Penambangan Jampang Kulon - Lipi),” J. Tek. Inform. Dan Sist. Inf., Vol. 2, No. 2, Pp. 162-172, 2016.

[8] P. Silitonga And I. S. Morina, “Analisis Qos ( Quality Of Service) Jaringan Kampus Dengan Menggunakan Microtic Routerboard ( Studi Kasus : Fakultas Ilmu Komputer Unika Santo Thomas S.U)," J. Times, Vol. Iii, No. 2, Pp. 19-24, 2014.

[9] Y. A. Pranata, I. Fibriani, And S. B. Utomo, “Analisis Optimasi Kinerja Quality Of Service Pada Layanan Komunikasi Data Menggunakan Ns - 2 Di Pt . Pln ( Persero ) Jember," Sinergi, Vol. 20, No. 2, Pp. 149-156, 2016.

[10] Z. Fajar, S. Putra, M. Sholeh, And N. Widyastuti, "Jurnal Jarkom Vol . 1 No . 2 Januari 2014 Issn : 2338-6312 Jurnal Jarkom Vol . 1 No . 2 Januari 2014 Issn : 2338-6312,” Vol. 1, No. 2, Pp. 174 184, 2014.

[11] S. G. M. Koo And S. W. Kwong, "Teaching Computer Communication Networks: Top-Down Or Bottom-Up?,” Front. Educ. 2005. Fie '05. Proc. 35th Annu. Conf., No. November 2005, P. S2h-S2h, 2005.

[12] Maria Ulfah Kurnia Dewi, "Maria Ulfa," Pp. 106-113, 2017.

[13] P. Cv, M. Putih, M. N. Ikhsanto, And H. W. Nugroho, "Analisis Performa Dan Desain Jaringan Komputer Menggunakan Top-Down Network Desain Studi Kasus Pada Cv. Merah Putih,” Vol. 01, No. 01, Pp. 69-82, 2015.

[14] I. Iskandar And A. Hidayat, "Analisa Quality Of Service ( Qos ) Jaringan Internet Kampus ( Studi Kasus : Uin Suska Riau ),” J. Corelit, Vol. 1, No. 2, Pp. 67-76, 2015.

[15] B. Sugiantoro And Y. B. Mahardhika, "Analisis Quality Of Service Jaringan Wireless Sukanet Wifi Di Fakultas Sains Dan Teknologi Uin Sunan Kalijaga,” J. Tek. Inform., Vol. 10, No. 2, 2018.

[16] W. Sugeng, J. E. Istiyanto, K. Mustofa, And A. Ashari, "The Impact Of Qos Changes Towards Network Performance,” Int. J. Comput. Networks Commun. Secur., Vol. 3, No. 2, Pp. 48-53, 2015.

[17] M. D. L. Siahaan, M. S. Panjaitan, And A. P. U. Siahaan, "Mikrotik Bandwidth Management To Gain The Users Prosperity Prevalent," Int. J. Eng. Trends Technol., Vol. 42, No. 5, Pp. 218-222, 2016.

[18] A. Rahman And H. Haviluddin, "Implementation Of Bandwidth Management Authentication," Int. J. Comput. Informatics, Vol. 1, No. 1, Pp. 1-8, 2016. 